\title{
Effect of oxygen inhalation on cerebral blood flow velocity in premature neonates
}

\author{
Sriparna Basu', Sandeep Barman', Ramchandra Shukla² and Ashok Kumar'
}

BACKGROUND: The study tested the hypothesis that hyperoxemia and hypoxemia differentially alter cerebral blood flow velocity (CBFV) in a gestational age-dependent manner.

METHODS: Cases comprised 98 neonates with mild respiratory distress, receiving oxygen for $>24 \mathrm{~h}$ in first $48 \mathrm{~h}$ of life. Ninety-eight age- and-weight-matched healthy neonates served as controls. Infants with perinatal asphyxia, shock, sepsis, malformations, acidosis/alkalosis, and hypo/hypercarbia were excluded. Resistance index (RI), pulsatility index (PI), peak systolic flow velocity (PSV), and vascular diameter were measured in internal carotid, vertebral, and middle cerebral arteries by transcranial doppler ultrasonography between 24 and $48 \mathrm{~h}$ of life with immediate postdoppler arterial blood gas analysis. For subgroup analysis, neonates were divided by gestational age and $\mathrm{PaO}_{2}$.

RESULTS: An overall decrease in RI/PI and increase in PSV and vasodilation was observed in cases. Hyperoxemia $\mathrm{PaO}_{2}$ $>90 \mathrm{~mm} \mathrm{Hg}$ ) was more common in premature neonates. Neonates $<32$ wk showed an increase in CBFV (decreased RI/PI and increased PSV/diameter) in association with hyperoxemia. An opposite response was observed in neonates $\geq 32 \mathrm{wk}$, where CBFV increased in response to hypoxemia $\left(\mathrm{PaO}_{2}<50 \mathrm{~mm} \mathrm{Hg}\right)$ and decreased in hyperoxemia. Increased CBFV showed high predictive accuracy for immediate mortality and intracranial hemorrhage.

CONCLUSION: Depending on gestational maturity, hyperoxemia or hypoxemia produce differential effects in CBFV.

G erminal matrix hemorrhage $(\mathrm{GMH})$, intraventricular hemorrhage (IVH), and periventricular leucomalacia (PVL) are well-known causes of impairment in neurodevelopment of premature, very low birth weight (BW) neonates $(1,2)$. Before $32 \mathrm{wk}$ of gestation, the blood vessels within the subependymal germinal matrix are fragile. Active corticogenesis during this period, which demands an increased cerebral blood flow (CBF) to meet the higher oxygen and nutrient demands of the developing brain $(3,4)$, makes these fragile vessels more prone to hemorrhage.

There is wide variation in CBF in sick neonates and the reasons are not completely understood. The concentrations of various blood gases are considered critical for the control of $\mathrm{CBF}$
(5) and both hypoxemia and hyperoxemia have been found to be responsible for its alteration (6). Cerebral autoregulation, a determining factor for the maintenance of $\mathrm{CBF}$, is also reportedly impaired in different hypoxemic and hyperoxemic conditions of sick premature neonates $(7,8)$. Moreover, knowledge of the utilization and safety of inhaled oxygen in this vulnerable group is limited. Although an exacerbation of GMH after hypoxemia has been observed in previous studies $(9,10)$, others report an association of a high fraction of inspired oxygen $\left(\mathrm{FiO}_{2}\right)$ and higher $\mathrm{CBF}$ with $\mathrm{IVH}(11,12)$.

We hypothesized that alteration in cerebral blood flow velocity (CBFV) might play an important role in the etiology of GMH-IVH and PVL. Its early detection can identify a subset of neonates vulnerable to cerebral hemorrhage and thus help in establishing an early management. The present study was conducted to identify any alteration of CBFV in response to changes in arterial oxygen tension in sick neonates receiving oxygen inhalation therapy for respiratory distress (RD) and to determine its prognostic significance.

\section{RESULTS}

Ninety-eight neonates with $\mathrm{RD}$ formed the final study group. An equal number of matched healthy neonates served as controls. The baseline maternal and neonatal parameters were comparable between the groups (Table 1). The various causes of $\mathrm{RD}$ included transient tachypnea of newborn $(n=42)$, respiratory distress syndrome (RDS; $n=36$ ). and meconium aspiration syndrome $(n=20)$. Mean arterial blood pressure remained above $35 \mathrm{~mm}$ of $\mathrm{Hg}$ in neonates $<32 \mathrm{wk}$ of age and above $50 \mathrm{~mm}$ of $\mathrm{Hg}$ in neonates $\geq 32 \mathrm{wk}$. Data were analyzed keeping normal $\mathrm{pH}(7.35-7.45)$ and partial pressure of carbondioxide $\left(\mathrm{PaCO}_{2}\right)(35-45)$ as covariates. None of the study neonates had intrauterine growth restriction, abnormal antenatal middle cerebral artery (MCA) blood flow or any evidence of GMH-IVH between 24 and $48 \mathrm{~h}$ of life.

Overall, a significant decrease in resistance index (RI) and pulsatility index (PI) and increase in peak systolic flow velocity (PSV) and diameters of all cerebral arteries was observed in the cases (Table 2). For further analysis, cases and controls were divided into two subgroups: subgroup I (gestational age $(\mathrm{GA})<32 \mathrm{wk} ; n=68)$ and subgroup II (GA $\geq 32 \mathrm{wk} ; n=30)$.

'Division of Neonatology, Department of Pediatrics, Institute of Medical Sciences, Banaras Hindu University, Varanasi, India; ${ }^{2}$ Department of Radiodiagnosis, Institute of Medical Sciences, Banaras Hindu University, Varanasi, India. Correspondence: Sriparna Basu (drsriparnabasu@rediffmail.com)

Received 30 October 2012; accepted 2 July 2013; advance online publication 8 January 2014. doi:10.1038/pr.2013.219 
Table 1. Comparison of neonatal and maternal demographic parameters between case and control groups

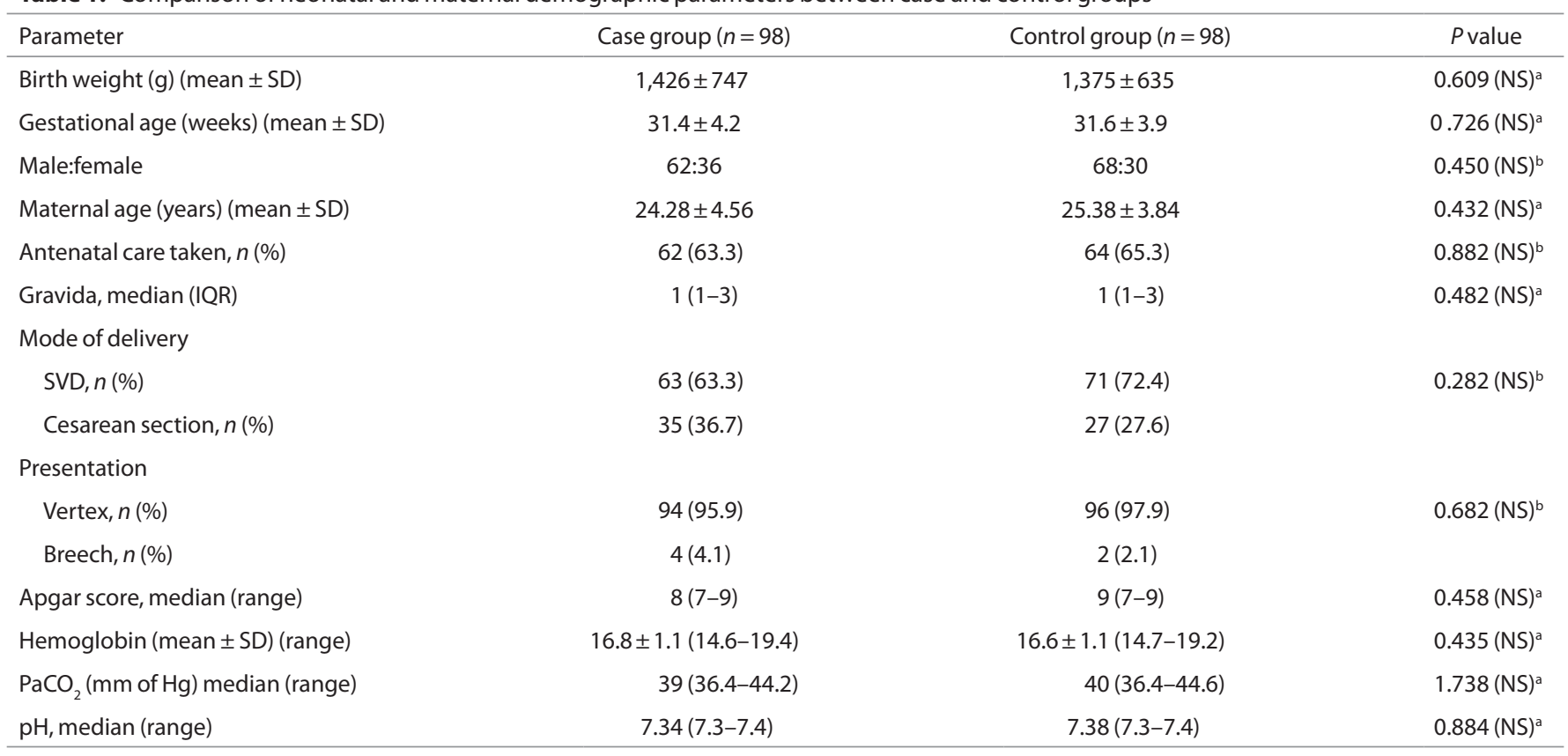

$\mathrm{IQR}$, interquartile range; NS, not significant; SVD, spontaneous vaginal delivery.

alndependent samples $T$ test. ${ }^{b} \chi^{2}$ test.

Table 2. Comparison of blood flow velocity of different cerebral arteries between case and control groups (mean \pm SD)

\begin{tabular}{|c|c|c|c|c|}
\hline \multirow[b]{2}{*}{ Parameter } & \multirow{2}{*}{$\begin{array}{l}\text { Case group } \\
\quad(n=98)\end{array}$} & \multirow{2}{*}{$\begin{array}{l}\text { Control group } \\
\quad(n=98)\end{array}$} & \multicolumn{2}{|c|}{$\begin{array}{l}\text { Independent } \\
\text { samples } T \text { test }\end{array}$} \\
\hline & & & $t$ value & $P$ value \\
\hline ICA RI & $0.71 \pm 0.24$ & $1.11 \pm 0.34$ & 9.487 & $<0.001$ \\
\hline VARI & $0.78 \pm 0.24$ & $1.16 \pm 0.32$ & 9.287 & $<0.001$ \\
\hline MCA RI & $0.83 \pm 0.25$ & $1.23 \pm 0.31$ & 9.775 & $<0.001$ \\
\hline ICA PI & $1.14 \pm 0.22$ & $1.52 \pm 0.28$ & 10.615 & $<0.001$ \\
\hline VAPI & $1.20 \pm 0.22$ & $1.57 \pm 0.25$ & 10.713 & $<0.001$ \\
\hline MCA PI & $1.26 \pm 0.23$ & $1.63 \pm 0.24$ & 10.964 & $<0.001$ \\
\hline ICA PSV $(\mathrm{cm} / \mathrm{s})$ & $52.68 \pm 22.95$ & $28.37 \pm 8.29$ & 9.860 & $<0.001$ \\
\hline VA PSV $(\mathrm{cm} / \mathrm{s})$ & $51.39 \pm 22.86$ & $27.15 \pm 8.15$ & 9.886 & $<0.001$ \\
\hline MCA PSV $(\mathrm{cm} / \mathrm{s})$ & $50.16 \pm 22.89$ & $25.97 \pm 8.09$ & 9.865 & $<0.001$ \\
\hline ICAD (mm) & $2.04 \pm 0.50$ & $1.86 \pm 0.58$ & 2.383 & $<0.05$ \\
\hline VA D $(\mathrm{mm})$ & $1.98 \pm 0.50$ & $1.77 \pm 0.59$ & 2.693 & $<0.01$ \\
\hline MCA D $(\mathrm{mm})$ & $1.92 \pm 0.51$ & $1.69 \pm 0.60$ & 2.857 & $<0.01$ \\
\hline
\end{tabular}

D, diameter; ICA, internal carotid artery; MCA, middle cerebral artery; PI, pulsatility index; PSV, peak systolic flow velocity; RI, resistance index; VA, vertebral artery.

Arterial blood gas (ABG) analysis of case subgroup I showed normal partial pressure of oxygen $\left(\mathrm{PaO}_{2} 50-90 \mathrm{~mm} \mathrm{Hg}\right)$ in 36 (52.9\%), hyperoxemia $\left(\mathrm{PaO}_{2}>90 \mathrm{~mm} \mathrm{Hg}\right)$ in $27(39.7 \%)$, and hypoxemia $\left(\mathrm{PaO}_{2}<50 \mathrm{~mm} \mathrm{Hg}\right)$ in $5(7.4 \%)$ neonates. The range of hypoxemia varied between 40 and $50 \mathrm{~mm} \mathrm{Hg}$. A lesser variation was observed in the $A B G$ analysis of case subgroup II: normal $\mathrm{PaO}_{2}$ was observed in 19 (63.3\%), hyperoxemia in 8 (26.7\%), and hypoxemia in $3(10 \%)$ neonates. No difference in hemoglobin and arterial oxygen saturation $\left(\mathrm{SaO}_{2}\right)$ was observed between the subgroups. The comparison of RI, PI, PSV, and diameters of all cerebral arteries between the case and control subgroups was shown in Table 3. Case subgroup I had decreased RI, PI and increased PSV and diameters of all cerebral arteries compared to controls $(P<0.001)$, while no such difference was observed in CBFV parameters between case subgroup II and controls except PSV, which was elevated in cases $(P<0.05)$.

Alteration of CBFV parameters with changes in $\mathrm{PaO}_{2}$ in case and control subgroup I was shown in Figure 1a-d. Case subgroup I (GA $<32 \mathrm{wk}$ ) with hyperoxemia showed a statistically significant decrease in resistance (RI and PI), increased PSV and vasodilation when compared to the hypoxemic and normoxemic neonates. However, there was no significant difference in CBFV parameters between hypoxemic and normoxemic neonates. The observation in case subgroup II (GA $\geq 32 \mathrm{wk}$ ) was opposite; a significant increase in resistance, decreased PSV and vasoconstriction was found in association with hyperoxemia, while decreased resistance, increased PSV and vasodilation was documented with hypoxemia (Figure 2a-d). A significant correlation was observed between changes in $\mathrm{PaO}_{2}$ and $\mathrm{CBFV}$ parameters (Table 4). Two neonates expired during the hospital stay. Both were of GA $<32 \mathrm{wk}$ and had grade III IVH in ultrasonography. Among the survivors $(n=$ 66), nine showed evidence of intracranial hemorrhage (seven GMH and two IVH). All of them had hyperoxemia in ABG analysis and increased CBFV when measured between 24 and $48 \mathrm{~h}$ of life (Table 5 ).

CBFV parameters showed $100 \%$ sensitivity and specificity as predictors of poor outcome in receiver-operating-characteristic curve analysis comparing neonates with poor prognosis (GMH-IVH and death) in case group and healthy controls 


\section{Articles | Basu etal.}

Table 3. Comparison of blood flow velocity of different cerebral arteries between case and control subgroups (mean \pm SD)

\begin{tabular}{|c|c|c|c|c|c|c|c|c|}
\hline \multirow[b]{2}{*}{ Parameter } & \multirow{2}{*}{$\begin{array}{l}\text { Case subgroup I } \\
(<32 \mathrm{wk})(n=68)\end{array}$} & \multirow{2}{*}{$\begin{array}{l}\text { Control subgroup } \\
\text { I }(<32 \mathrm{wk})(n=68)\end{array}$} & \multicolumn{2}{|c|}{$\begin{array}{c}\text { Independent samples } \\
\text { T test }\end{array}$} & \multirow{2}{*}{$\begin{array}{l}\text { Case subgroup II } \\
(\geq 32 \mathrm{wk})(n=30)\end{array}$} & \multirow{2}{*}{$\begin{array}{l}\text { Control subgroup } \\
\text { II ( } \geq 32 \mathrm{wk})(n=30)\end{array}$} & \multicolumn{2}{|c|}{$\begin{array}{c}\text { Independent samples } \\
T \text { test }\end{array}$} \\
\hline & & & $t$ value & $P$ value & & & $t$ value & $P$ value \\
\hline Gestational age (weeks) & $28.9 \pm 1.5$ & $29.4 \pm 1.4$ & 2.096 & 0.989 & $37.1 \pm 2.7$ & $36.6 \pm 3.1$ & 0.370 & 0.713 (NS) \\
\hline ICA RI & $0.78 \pm 0.19$ & $1.31 \pm 0.14$ & 18.556 & $<0.001$ & $0.63 \pm 0.29$ & $0.60 \pm 0.19$ & 0.412 & 0.682 (NS) \\
\hline ICA PI & $1.18 \pm 0.18$ & $1.68 \pm 0.12$ & 18.214 & $<0.001$ & $1.04 \pm 0.28$ & $1.0 \pm 0.19$ & 0.515 & 0.609 (NS) \\
\hline VAPI & $1.24 \pm 0.19$ & $1.72 \pm 0.12$ & 17.194 & $<0.001$ & $1.10 \pm 0.28$ & $1.05 \pm 0.18$ & 0.939 & 0.352 (NS) \\
\hline MCA PI & $1.29 \pm 0.20$ & $1.77 \pm 0.11$ & 16.758 & $<0.001$ & $1.16 \pm 0.28$ & $1.10 \pm 0.19$ & 1.056 & 0.295 (NS) \\
\hline ICA PSV (cm/s) & $54.35 \pm 3.94$ & $23.70 \pm 2.41$ & 10.498 & $<0.001$ & $50.25 \pm 18.73$ & $42.44 \pm 8.93$ & 2.061 & $<0.05$ \\
\hline VA D $(\mathrm{mm})$ & $1.81 \pm 0.20$ & $1.40 \pm 0.13$ & 13.855 & $<0.001$ & $2.41 \pm 0.68$ & $2.32 \pm 0.51$ & 0.588 & 0.559 (NS) \\
\hline $\operatorname{MCAD}(\mathrm{mm})$ & $1.75 \pm 0.21$ & $1.30 \pm 0.15$ & 14.295 & $<0.001$ & $2.34 \pm 0.68$ & $2.21 \pm 0.52$ & 0.785 & 0.436 (NS) \\
\hline
\end{tabular}

D, diameter; ICA, internal carotid artery; MCA, middle cerebral artery; NS, not significant; PI, pulsatility index; PSV, peak systolic flow velocity; RI, resistance index; VA, vertebral artery.

a

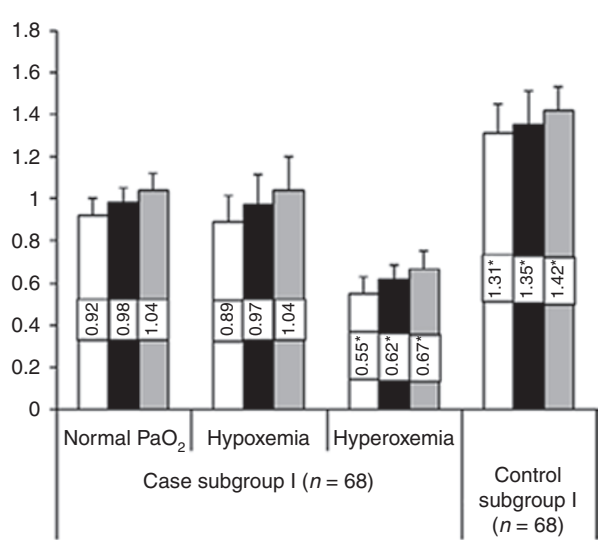

C

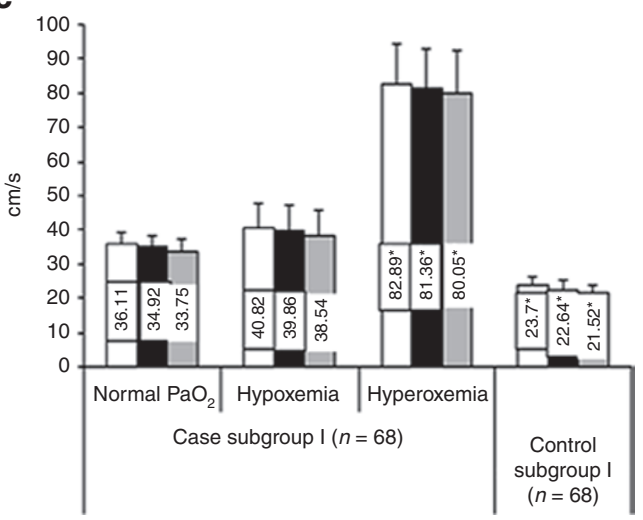

b

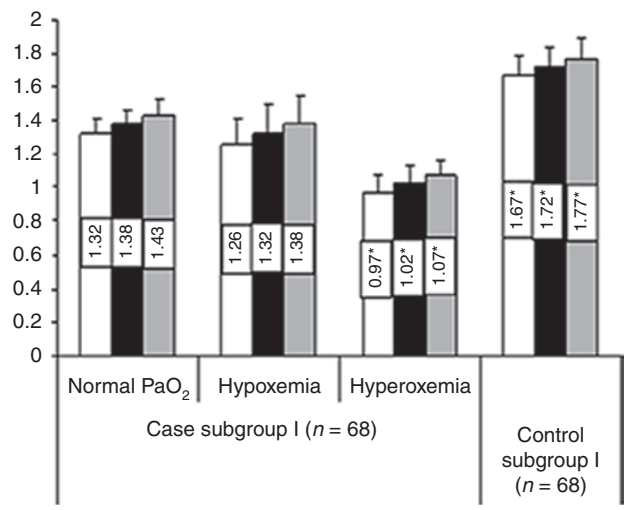

d

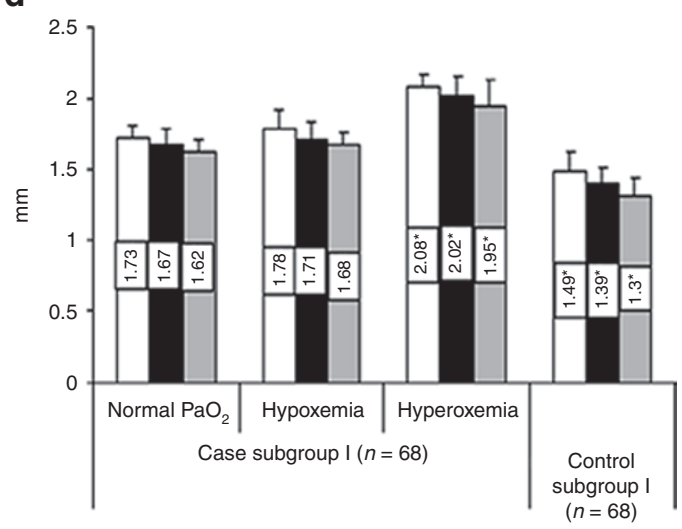

Figure 1. Comparison of (a) resistance index (RI), (b) pulsatility index (PI), (c) peak systolic flow velocity (PSV), and (d) diameter of internal carotid artery (ICA), vertebral artery (VA), and middle cerebral artery (MCA) between case and control subgroup I (gestational age $<32 \mathrm{wk}$ ) based on PaO ${ }_{2}$ (mean \pm SD). ICA, white columns; VA, black columns; $\mathrm{MCA}$, gray columns. $\mathrm{PaO}_{2^{\prime}}$ partial pressure of oxygen. Normal $\mathrm{PaO}_{2}(50-90 \mathrm{~mm}$ of $\mathrm{Hg})(n=37)$, hypoxemia $\left(\mathrm{PaO}{ }_{2}\right.$ $<50 \mathrm{~mm}$ of $\mathrm{Hg})(n=5)$, and hyperoxemia $\left(\mathrm{PaO}_{2}>90 \mathrm{~mm}\right.$ of Hg) $(n=26)$. ${ }^{*}$ Statistically significant difference $(P<0.05)$. 
a

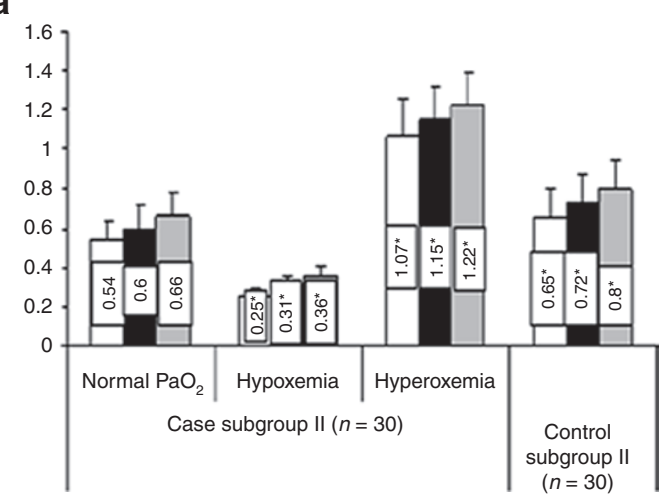

C

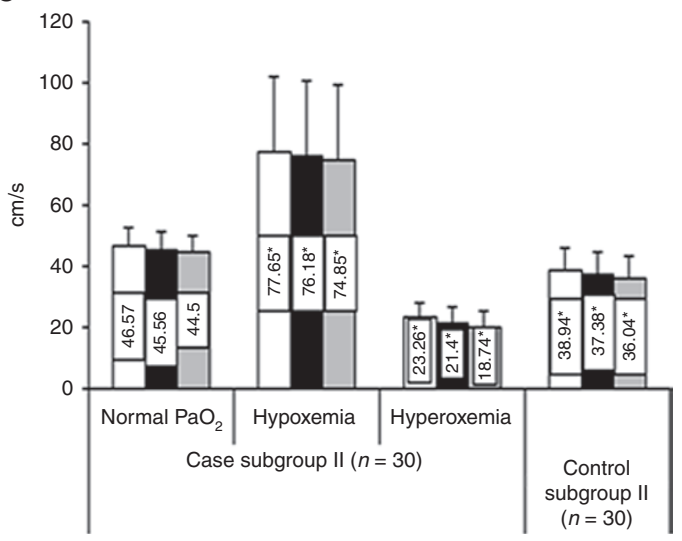

b

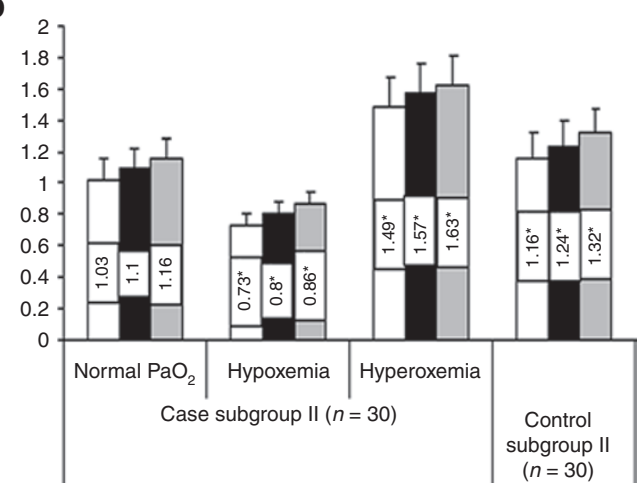

d

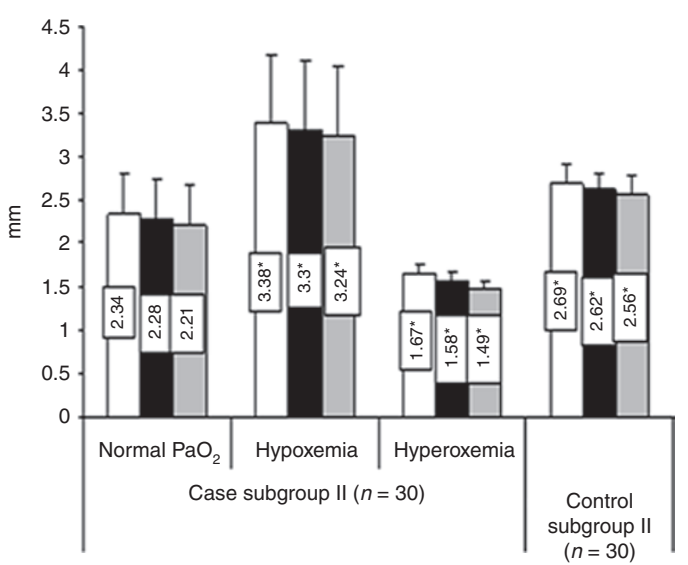

Figure 2. Comparison of (a) resistance index (RI), (b) pulsatility index (PI), (c) peak systolic flow velocity (PSV), and (d) diameter of internal carotid artery (ICA), vertebral artery (VA), and middle cerebral artery (MCA) between case and control subgroup II (gestational age $\geq 32 \mathrm{wk}$ ) (mean \pm SD). ICA, white columns; VA, black columns; MCA, gray columns. Normal $\mathrm{PaO}_{2}(n=19)$, hypoxemia $(n=6)$, and hyperoxemia $(n=5)$. * Statistically significant difference $(P<0.05)$.

Table 4. Pearson correlation test between partial pressure of oxygen $\left(\mathrm{PaO}_{2}\right)$ in arterial blood and different parameters of cerebral blood flow velocity

\begin{tabular}{|c|c|c|c|c|c|c|c|c|c|c|c|c|}
\hline & ICA RI & VA RI & MCA RI & ICA PI & VAPI & MCA PI & ICAPSV & VA PSV & MCAPSV & ICAD & VAD & MCAD \\
\hline $\mathrm{PaO}_{2}$ & $0.849^{*}$ & $0.855^{*}$ & $0.874^{*}$ & $0.847^{*}$ & $0.854^{*}$ & $0.844^{*}$ & $0.854^{*}$ & $0.853^{*}$ & $0.853^{*}$ & $0.771^{*}$ & $0.734^{*}$ & $0.651^{*}$ \\
\hline ICA RI & 1 & $0.993^{*}$ & $0.988^{*}$ & $0.951^{*}$ & $0.949^{*}$ & $0.947^{*}$ & $0.924^{*}$ & $0.925^{*}$ & $0.924^{*}$ & $0.898^{*}$ & $0.841^{*}$ & $0.743^{*}$ \\
\hline MCA RI & - & - & 1 & $0.951^{*}$ & $0.948^{*}$ & $0.946^{*}$ & $0.908^{*}$ & $0.908^{*}$ & $0.908^{*}$ & $0.88^{*}$ & $0.820^{*}$ & $0.719^{*}$ \\
\hline ICA PI & - & - & - & 1 & $0.995^{*}$ & $0.986^{*}$ & $0.900^{*}$ & $0.901^{*}$ & $0.902^{*}$ & $0.882^{*}$ & $0.830^{*}$ & $0.735^{*}$ \\
\hline MCA PI & - & - & - & - & - & 1 & $0.901 *$ & $0.902^{*}$ & $0.902^{*}$ & $0.874^{*}$ & $0.826^{*}$ & $0.741^{*}$ \\
\hline ICAPSV & - & - & - & - & - & - & 1 & $1.000^{*}$ & $0.999^{*}$ & $0.937^{*}$ & $0.890^{*}$ & $0.784^{*}$ \\
\hline VAPSV & - & - & - & - & - & - & - & 1 & $1.000^{*}$ & $0.937^{*}$ & $0.889^{*}$ & $0.781 *$ \\
\hline MCA PSV & - & - & - & - & - & - & - & - & 1 & $0.937^{*}$ & $0.888^{*}$ & $0.777^{*}$ \\
\hline$I C A D$ & - & - & - & - & - & - & - & - & - & 1 & $0.955^{*}$ & $0.839 *$ \\
\hline
\end{tabular}

D, diameter; ICA, internal carotid artery; MCA, middle cerebral artery; PI, pulsatility index; PSV, peak systolic flow velocity; RI, resistance index; VA, vertebral artery. ${ }^{*} P<0.001$.

(Table 6). On follow up, delayed developmental milestones was observed in two neonates. Both of them had evidence of IVH in the neonatal period and obstructed hydrocephalus in magnetic resonance imaging at $6 \mathrm{mo}$. Development was normal in neonates who had GMH. There was no difference in the alteration of CBFV and incidence of GMH-IVH between males and females of the study group (data not shown). None of the neonates developed patent ductus arteriosus, retinopathy 
Table 5. Comparison of blood flow velocity of different cerebral arteries between study subgroups (normal outcome vs. GMH-IVH/ expired) (mean \pm SD)

\begin{tabular}{|c|c|c|c|c|}
\hline \multirow[b]{2}{*}{ Parameter } & \multirow{2}{*}{$\begin{array}{l}\text { Normal outcome } \\
\text { group }(n=57)\end{array}$} & \multirow{2}{*}{$\begin{array}{l}\text { GMH-IVH/expired } \\
\text { group }(n=11)\end{array}$} & \multicolumn{2}{|c|}{$\begin{array}{l}\text { Independent } \\
\text { samples } T \text { test }\end{array}$} \\
\hline & & & $t$ value & $P$ value \\
\hline ICA RI & $0.86 \pm 0.14$ & $0.49 \pm 0.04$ & 8.952 & $<0.001$ \\
\hline VARI & $0.92 \pm 0.14$ & $0.55 \pm 0.04$ & 8.703 & $<0.001$ \\
\hline MCA RI & $0.98 \pm 0.15$ & $0.61 \pm 0.05$ & 8.505 & $<0.001$ \\
\hline ICA PI & $1.26 \pm 0.14$ & $0.91 \pm 0.05$ & 8.244 & $<0.001$ \\
\hline VAPI & $1.32 \pm 0.14$ & $0.96 \pm 0.05$ & 8.836 & $<0.001$ \\
\hline MCAPI & $1.38 \pm 0.15$ & $1.00 \pm 0.07$ & 8.282 & $<0.001$ \\
\hline ICA PSV (cm/s) & $42.90 \pm 13.22$ & $91.04 \pm 4.28$ & 11.819 & $<0.001$ \\
\hline VA PSV $(\mathrm{cm} / \mathrm{s})$ & $41.67 \pm 13.00$ & $89.64 \pm 4.43$ & 11.959 & $<0.001$ \\
\hline MCA PSV $(\mathrm{cm} / \mathrm{s})$ & $40.36 \pm 12.70$ & $88.60 \pm 4.35$ & 12.315 & $<0.001$ \\
\hline ICA D (mm) & $1.80 \pm 0.13$ & $2.15 \pm 0.09$ & 8.194 & $<0.001$ \\
\hline $\operatorname{VAD}(\mathrm{mm})$ & $1.74 \pm 0.16$ & $2.06 \pm 0.09$ & 6.229 & $<0.001$ \\
\hline $\operatorname{MCAD}(\mathrm{mm})$ & $1.68 \pm 0.20$ & $1.94 \pm 0.09$ & 4.104 & $<0.001$ \\
\hline
\end{tabular}

$\mathrm{D}$, diameter; ICA, internal carotid artery; MCA, middle cerebral artery; PI, pulsatility index; PSV, peak systolic flow velocity; RI, resistance index; VA, vertebral artery.

of prematurity, bronchopulmonary dysplasia, or necrotizing enterocolitis during the hospital stay.

\section{DISCUSSION}

In the fetal life, optimal CBF and cerebral oxygen consumption are essential for neural growth and development (13). It has been observed in experimental animals that hyperoxemia increases apoptotic cell death and white matter damage $(14,15)$. The vulnerability to oxygen-induced cell death is age dependent and the maximal incidence is observed during the first week of life (16). The oxygen delivery to the brain depends on the cerebral hemodynamics, concentration of inhaled oxygen and the pulmonary gas exchange (17). The term "cerebral hemodynamics" includes CBF, CBFV, and cerebral blood volume. Preterm neonates demonstrate poorly developed vascular border zone in periventricular white matter and immature germinal matrix, which make them vulnerable to cerebral hemorrhage and ischemic injury (3). Disturbance of cerebral hemodynamics compromises cerebrovascular integrity in these neonates. Therefore, a balanced cerebral hemodynamics is pivotal in preventing such complications (18). Measurement by tissue oxygenation by near infrared spectroscopy may be used as a surrogate for measurement of CBF, although its availability is limited. In developing countries, measurement of CBFV by transcranial color doppler (TCD) can be utilized as an effective alternative to monitor and guide further therapy.

Cerebral autoregulation limits $\mathrm{CBF}$ variation over a range of cerebral perfusion pressures (19) and is a key physiologic mechanism for ensuring perfusion and oxygenation of the brain. In the preterm brain, however, the presence and the characteristics of cerebral autoregulation are still poorly understood despite intensive research. A number of studies have suggested that cerebral autoregulation is lost in the sick preterm infants, predisposing them to hemorrhagic and ischemic insult (20-22). Previous studies have also shown a strong correlation of RD in newborns with low and fluctuating arterial blood pressure which in turn is directly linked to the maintenance of CBF (23).

In the present study, a GA of $32 \mathrm{wk}$ was taken as the cutoff for subgroup analysis as blood vessels within the germinal matrix remain fragile till $32 \mathrm{wk}$ of gestation $(3,4)$. Cranial ultrasonographic examination was performed frequently, to detect GMH-IVH at the earliest. The possible reasons for differential response to hypoxemia and hyperoxemia at different GA could be many: poor cerebrovascular autoregulation, hyperoxemia mediated oxidative stress in presence of poor defense in premature neonates, local production of vasodilators like nitric oxide or direct vasoparalysis by hyperoxemia. A few studies have examined the effect of hyperoxemia on CBFV in premature neonates. Tsuji et al. has documented high oxygen saturation in association with impaired cerebrovascular autoregulation and severe GMH-IVH/PVL (22). A couple of studies have documented a fall in CBFV in premature infants with hyperoxemia $(24,25)$. Niijima et al. observed a fall in CBFV in $88 \%$ premature infants in response to a transient threefold increase in oxygen tension (24). Leahy et al., by using a modified venous occlusion plethysmography technique, observed significant decrease in $\mathrm{CBF}$ in premature neonates after inhalation of $100 \%$ oxygen (25). Both these studies involved healthy neonates whose response might essentially vary from that of the sick neonates recruited in the present study.

In the present study, a significant increase in the CBF was observed in the neonates who developed GMH-IVH and those who died. In this regard, observations made by different authors vary. Linder $e t$ al. have found high fraction of inspired oxygen to be significantly associated with an increased risk of IVH (11), and Pellicer et al. have observed higher CBF in infants with IVH compared to those without (12). Contrary to this observation, Meek et al. recorded decreased CBF in association with GMH-IVH (26), while the work of Ment et al. demonstrates an overall decrease in CBF in early GMH-IVH, but surprisingly had unilateral higher blood flow in the cerebral hemisphere having hemorrhage (27). In terms of the relation between $\mathrm{CBF}$ and mortality, Ojala et al. observed lower resistance in CBF during early circulatory transition associated with adverse outcome in nonventilated preterm infants (28). Baenziger et al. reported higher basal CBF in early neonatal period in preterm infants, who survived 18 mo compared to those who expired (29). No evidence of PVL was found in magnetic resonance imaging examination of the brain of any neonate in the present study. PVL occur mostly from severe hypoxia, which was uncommon in our study.

Since the possible causes which might have altered CBFV, like perinatal asphyxia, shock, mechanical ventilation, patent ductus arteriosus, acidosis/alkalosis, hypo/hypercarbia, and other systemic diseases were excluded in the present study, the association between hypo/hyperoxemia and the changes in $\mathrm{CBFV}$ can be considered as reasonably fair. Similarly, neonates with ear-onset neonatal sepsis and intrauterine pneumonia 
Table 6. Validity indices for different parameters of cerebral blood flow velocity

\begin{tabular}{lcccc}
\hline Parameter & $\begin{array}{c}\text { Area under } \\
\text { the curve }\end{array}$ & Cut-off & $\begin{array}{c}\text { Sensitivity } \\
(\%)\end{array}$ & $\begin{array}{c}\text { Specificity } \\
(\%)\end{array}$ \\
\hline ICA RI & 1.000 & $\leq 0.76$ & 100 & 100 \\
VA RI & 1.000 & $\leq 0.84$ & 100 & 100 \\
MCA RI & 1.000 & $\leq 0.92$ & 100 & 100 \\
ICA PI & 1.000 & $\leq 1.17$ & 100 & 100 \\
VAPI & 1.000 & $\leq 1.22$ & 100 & 100 \\
MCA PI & 1.000 & $\leq 1.29$ & 100 & 100 \\
ICA PSV (cm/s) & 1.000 & $\geq 56.2$ & 100 & 100 \\
VAPSV $(\mathrm{cm} / \mathrm{s})$ & 1.000 & $\geq 51.8$ & 100 & 100 \\
MCA PSV (cm/s) & 1.000 & $\geq 46.4$ & 100 & 100 \\
ICA D $(\mathrm{mm})$ & 1.000 & $\geq 2.1$ & 100 & 100 \\
VA D $(\mathrm{mm})$ & 1.000 & $\geq 2.0$ & 100 & 100 \\
MCA D $(\mathrm{mm})$ & 1.000 & $\geq 1.8$ & 100 & 100 \\
\hline
\end{tabular}

D, diameter; ICA, internal carotid artery; MCA, middle cerebral artery; PI, pulsatility index; PSV, peak systolic flow velocity; RI, resistance index; VA, vertebral artery.

(30) and hypo/hypercarbia (31) which possibly affect CBFV were excluded. Moreover, hemoglobin concentration and $\mathrm{SaO}_{2}$, which might influence the results, were also comparable between the groups. Increase in CBFV was independent of other variables like demographic profile and management protocol as both the groups were comparable in these regards. However, ABG analysis for normal healthy controls was not done for ethical issues. In order to rule out observer variation in the ultrasonographic examination and issues of reproducibility, a single observer performed all the doppler examinations and each parameter was measured three times and the mean was taken.

The present study however was not devoid of limitations. Although TCD ultrasound is a noninvasive, cheap, easily available bedside device to assess CBFV, sonographic measurement of the parameters is difficult in small caliber vessels like the MCA. It was also not possible to blind the radiologist regarding the patient, as oxygen supplementation was obvious, but he was not aware of the ABG findings and the subgroup to which the neonate belonged. He was also not involved in any data entry and statistical analysis. The changes in CBFV were assessed only once during the study. Serial measurements over time would have been more informative of the evolution of changes in $\mathrm{CBF}$.

Uncertainty remains regarding the target $\mathrm{SpO}_{2}$ values in preterm, very low $\mathrm{BW}$ infants. Higher $\mathrm{SpO}_{2}$ targets may induce stable sleep patterns and better long-term growth and development (32), but at the cost of retinopathy of prematurity, bronchopulmonary dysplasia, and brain injury $(33,34)$. Alternately, the use of "restrictive" oxygen therapy has been found to produce a negative effect on the survival, cognitive functions, adaptive skills and behavior (35). Current trials like SUPPORT (36) and BOOST II (37) have demonstrated that both "low" and "high" saturation ranges are associated with definite complications. Although pulse oximetry is considered as the "fifth vital sign" for continuous and noninvasive monitoring of oxygen levels (38), the ability of pulse oximeter to reliably detect hyperoxemia remains controversial $(39,40)$.

To conclude, the present study demonstrates that depending on gestational maturity, hyperoxemia, and hypoxemia produce differential effects in CBFV. Hyperoxemia is common in preterm very low $\mathrm{BW}$ neonates in spite of strict maintenance of $\mathrm{SpO}_{2}$ over a narrow range. Increase in $\mathrm{PaO}_{2}$ correlates with increase in $\mathrm{CBFV}$, which is a risk factor of mortality and GMHIVH. Therefore, caution should be entertained while using supplemental oxygen in this vulnerable group. TCD ultrasonography may be utilized as a bedside, noninvasive, easily available and reasonably accurate tool to assess CBFV. CBFV and its changes may be used as a prognostic parameter for cerebral hemorrhage and immediate mortality in sick premature neonates receiving oxygen inhalation therapy for $\mathrm{RD}$.

\section{METHODS}

A prospective cohort study was carried out in the neonatal intensive care unit of the university teaching hospital over a period of $18 \mathrm{mo}$, from September 2009 to February 2011.

\section{Selection of Study Group}

The study group comprised of consecutive recruitment of neonates of all GA and BWs, who were admitted in neonatal intensive care unit with mild RD within $6 \mathrm{~h}$ of birth and who received oxygen inhalation for more than $24 \mathrm{~h}$ in first $48 \mathrm{~h}$ of life. Mild RD was defined by Downe score 3-5 (41). Oxygen inhalation was started at Downe score three or more and was provided either by hood or nasal prongs. The $\mathrm{FiO}_{2}$ was adjusted to target an oxygen saturation of $88-93 \%$ by pulse oximetry.

An equal number of healthy neonates, matched for BW, GA, and postnatal age formed the control group. Neonates with perinatal asphyxia, ear-onset neonatal sepsis, shock requiring vasopressor support, anemia (hematocrit $<35 \%$ ), heart disease, and major congenital malformations were excluded. Neonates in whom RD increased to moderate to severe degree (Downe score $>5$ ), requiring continuous positive airway pressure or ventilatory support were also excluded. Written informed consents were taken from all parents for participation in the study. The study was approved by the Institute of Medical Sciences, Banaras Hindu University, India ethics committee.

\section{Sample Size Calculation}

Assuming the confidence limit $(\alpha)$ of $95 \%$ and an absolute precision (d) of $10 \%$, the minimum sample size of the study group was calculated to be 92 .

\section{Clinical Profile and Investigations}

Detailed antenatal and perinatal history were recorded. BW was taken soon after delivery. GA was assessed from maternal history of last menstrual period, antenatal ultrasonography, and modified Ballard score (42). Downe score was calculated at admission and hourly thereafter. According to the neonatal intensive care unit protocol of our hospital, intravenous ampicillin and amikacin were started at the onset of RD and stopped once ear-onset neonatal sepsis was excluded. Continuous monitoring of oxygen saturation $\left(\mathrm{SpO}_{2}\right)$ by pulse oximetry and hourly monitoring of temperature, heart rate, mean arterial blood pressure, and capillary filling time were done. Investigations including sepsis screen (total leucocyte count, absolute neutrophil count, immature to total neutrophil ratio, micro-ESR, and C-reactive protein), blood culture and sensitivity, and chest x-ray were done at admission. In presence of clinical suspicion of meningitis, a cerebrospinal fluid examination was done. RDS was diagnosed on the chest $\mathrm{x}$-ray findings and from the clinical course. Transient tachypnea of newborn was diagnosed when the neonates made a spontaneous recovery within first $48 \mathrm{~h}$ of life and had a characteristic chest $\mathrm{x}$-ray. Meconium aspiration syndrome was diagnosed on the basis of history of delivery through meconium-stained amniotic fluid and development of $\mathrm{RD}$ within $6 \mathrm{~h}$ 
after birth in the absence of any other demonstrable cause. Sequential blood sugar levels, hematocrit, platelet count, ABG, blood urea, and serum creatinine and serum electrolytes were estimated. An abdominal x-ray and/or ultrasonography and echocardiography were done as and when necessary as a part of ongoing supportive care.

$\mathrm{CBFV}$ was measured in the internal carotid artery, vertebral artery, and MCA after $24 \mathrm{~h}$ of oxygen inhalation and within the first $48 \mathrm{~h}$ of life. In the study group, ABG analysis was done immediately after completion of the assessment of CBFV. The neonates with metabolic or respiratory acidosis/alkalosis and hypo/hypercarbia were excluded. Cranial ultrasonography was done once within the first $24 \mathrm{~h}$ of birth to exclude any intracranial pathology and malformation. Thereafter, it was done every $24 \mathrm{~h}$ until the oxygen inhalation was stopped and then every $48 \mathrm{~h}$ till discharge to detect any GMH-IVH and PVL. GMH-IVH was classified according to the criteria of Volpe (43). After discharge from the hospital, cranial ultrasonography was done weekly till the postconceptional age of $40 \mathrm{wk}$ and then monthly till the age of 6 mo.

Detailed in-hospital progress and outcome were recorded. Screening for retinopathy of prematurity was done initially at the age of $34 \mathrm{wk}$ and then every $2 \mathrm{wk}$ till $40 \mathrm{wk}$. Follow up was done for a minimum period of 6 mo. A computerized tomographic scan or an magnetic resonance imaging examination of the head was done at the age of 6 mo.

\section{Assessment of CBFV}

CBFV was assessed by TCD ultrasonography (TOSHIBA NEMIO30). A single observer (R.S.) performed all TCD examinations. RI, PI, PSV, and vascular diameter (D) were measured in bilateral internal carotid artery, vertebral artery and MCA using a high frequency linear array $8 \mathrm{MHz}$ (for internal carotid artery and vertebral artery) and a curvilinear array $3.75 \mathrm{MHz}$ (for MCA) transducers. MCA were focused through the anterior fontanel, internal carotid artery were focused from midline with extended neck, while vertebral artery were focused with extended neck in the right or left lateral position for the respective sides. All measurements were done without any pressure provocation and in quiet neonates. An oral dose of 50\% dextrose was used as pacifier. RI and PI were calculated using standard formulae (44). Each parameter was assessed thrice and the mean value was obtained. In the absence of any difference between the values of RI, PI, PSV, and diameter of both sides of the same artery, a mean value was taken for each parameter.

\section{Statistical Analysis}

The statistical program SPSS version 16.0 (SPSS, Chicago, IL) was used for data entry and analysis. The data were presented as mean $\pm \mathrm{SD}$ and median (range) for continuous variables and as frequency and percentage for categorical variables. Comparison between two groups was done using independent samples $T$ test for continuous variables and $\chi^{2}$ test for categorical data. Analysis of variance and post hoc analysis (Bonferroni test) were use to compare variables among multiple groups. Pearson correlation coefficient was calculated to detect the correlation between $\mathrm{PaO}_{2}$ values and CBFV parameters. Sensitivity and specificity of different CBFV parameters were calculated at different selected cut-off values for CBFV. Receiver-operatingcharacteristic curve analyses with measurement of area under the curve were performed to identify the appropriate cut-off values. A $P$ value of $<0.05$ was considered statistically significant.

\section{STATEMENT OF FINANCIAL SUPPORT}

No financial assistance was received to support this study.

Disclosure: The authors declare no conflict of interest.

\section{REFERENCES}

1. de Vries LS, Eken P, Dubowitz LM. The spectrum of leukomalacia using cranial ultrasound. Behav Brain Res 1992;49:1-6.

2. De Vries LS, Van Haastert IL, Rademaker KJ, Koopman C, Groenendaal F. Ultrasound abnormalities preceding cerebral palsy in high-risk preterm infants. J Pediatr 2004;144:815-20.

3. Baburamani AA, Ek CJ, Walker DW, Castillo-Melendez M. Vulnerability of the developing brain to hypoxic-ischemic damage: contribution of the cerebral vasculature to injury and repair? Front Physiol 2012;3:424.
4. Trommer BL, Groothuis DR, Pasternak JF. Quantitative analysis of cerebral vessels in the newborn puppy: the structure of germinal matrix vessels may predispose to hemorrhage. Pediatr Res 1987;22:23-8.

5. Nishimura N, Iwasaki K, Ogawa Y, Shibata S. Oxygen administration, cerebral blood flow velocity, and dynamic cerebral autoregulation. Aviat Space Environ Med 2007;78:1121-7.

6. Macri MA, D’Alessandro N, Di Giulio C, et al. Region-specific effects on brain metabolites of hypoxia and hyperoxia overlaid on cerebral ischemia in young and old rats: a quantitative proton magnetic resonance spectroscopy study. J Biomed Sci 2010;17:14.

7. Iwasaki K, Ogawa Y, Shibata S, Aoki K. Acute exposure to normobaric mild hypoxia alters dynamic relationships between blood pressure and blood flow at very low frequency. J Cereb Blood Flow Metab 2007;27:776-84.

8. Riyas PK, Vijayakumar KM, Kulkarni ML. Neonatal mechanical ventilation. Indian J Pediatr 2003;70:537-40.

9. Kamei A, Houdou S, Mito T, Konomi H, Takashima S. Developmental change in type VI collagen in human cerebral vessels. Pediatr Neurol 1992;8:183-6.

10. Ballabh P. Intraventricular hemorrhage in premature infants: mechanism of disease. Pediatr Res 2010;67:1-8.

11. Linder N, Haskin O, Levit $\mathrm{O}$, et al. Risk factors for intraventricular hemorrhage in very low birth weight premature infants: a retrospective casecontrol study. Pediatrics 2003;111(5 Pt 1):e590-5.

12. Pellicer A, Valverde E, Gayá F, Quero J, Cabañas F. Postnatal adaptation of brain circulation in preterm infants. Pediatr Neurol 2001;24:103-9.

13. Lee SJ, Hatran DP, Tomimatsu T, Peña JP, McAuley G, Longo LD. Fetal cerebral blood flow, electrocorticographic activity, and oxygenation: responses to acute hypoxia. J Physiol (Lond) 2009;587(Pt 9): 2033-47.

14. Gerstner B, DeSilva TM, Genz K, et al. Hyperoxia causes maturation-dependent cell death in the developing white matter. J Neurosci 2008;28:1236-45.

15. Vottier G, Pham H, Pansiot J, et al. Deleterious effect of hyperoxia at birth on white matter damage in the newborn rat. Dev Neurosci 2011;33: 261-9.

16. Bittigau P, Sifringer M, Genz K, et al. Antiepileptic drugs and apoptotic neurodegeneration in the developing brain. Proc Natl Acad Sci USA 2002;99:15089-94.

17. Pena JP, Tomimatsu T, Hatran DP, McGill LL, Longo LD. Cerebral blood flow and oxygenation in ovine fetus: responses to superimposed hypoxia at both low and high altitude. J Physiol (Lond) 2007;578(Pt 1):359-70.

18. Liem KD, Greisen G. Monitoring of cerebral haemodynamics in newborn infants. Early Hum Dev 2010;86:155-8.

19. Lassen NA. Cerebral blood flow and oxygen consumption in man. Physiol Rev 1959;39:183-238.

20. Caicedo A, De Smet D, Vanderhaegen J, et al. Impaired cerebral autoregulation using near-infrared spectroscopy and its relation to clinical outcomes in premature infants. Adv Exp Med Biol 2011;701:233-9.

21. Lou HC, Lassen NA, Friis-Hansen B. Impaired autoregulation of cerebral blood flow in the distressed newborn infant. J Pediatr 1979;94:118-21.

22. Tsuji M, Saul JP, du Plessis A, et al. Cerebral intravascular oxygenation correlates with mean arterial pressure in critically ill premature infants. Pediatrics 2000;106:625-32.

23. Nishimura N, Iwasaki K, Ogawa Y, Aoki K. Decreased steady-state cerebral blood flow velocity and altered dynamic cerebral autoregulation during 5-h sustained 15\% O2 hypoxia. J Appl Physiol 2010;108:1154-61.

24. Niijima S, Shortland DB, Levene MI, Evans DH. Transient hyperoxia and cerebral blood flow velocity in infants born prematurely and at full term. Arch Dis Child 1988;63(10 Spec No):1126-30.

25. Leahy FA, Cates D, MacCallum M, Rigatto H. Effect of CO2 and $100 \% \mathrm{O} 2$ on cerebral blood flow in preterm infants. J Appl Physiol Respir Environ Exerc Physiol 1980;48:468-72.

26. Meek JH, Tyszczuk L, Elwell CE, Wyatt JS. Low cerebral blood flow is a risk factor for severe intraventricular haemorrhage. Arch Dis Child Fetal Neonatal Ed 1999;81:F15-8.

27. Ment LR, Ehrenkranz RA, Lange RC, Rothstein PT, Duncan CC. Alterations in cerebral blood flow in preterm infants with intraventricular hemorrhage. Pediatrics 1981;68:763-9. 
28. Ojala T, Kääpä P, Helenius $H$, et al. Low cerebral blood flow resistance in nonventilated preterm infants predicts poor neurologic outcome. Pediatr Crit Care Med 2004;5:264-8.

29. Baenziger O, Mueller AM, Morales CG, et al. Cerebral blood flow and neurological outcome in the preterm infant. Eur J Pediatr 1999;158:138-43.

30. Basu S, Dewangan S, Shukla RC, Anupurva S, Kumar A. Cerebral blood flow velocity in early-onset neonatal sepsis and its clinical significance. Eur J Pediatr 2012;171:901-9.

31. Payne SJ, Selb J, Boas DA. Effects of autoregulation and $\mathrm{CO} 2$ reactivity on cerebral oxygen transport. Ann Biomed Eng 2009;37:2288-98.

32. Tin W, Gupta S. Optimum oxygen therapy in preterm babies. Arch Dis Child Fetal Neonatal Ed 2007;92:F143-7.

33. Deuber C, Terhaar M. Hyperoxia in very preterm infants: a systematic review of the literature. J Perinat Neonatal Nurs 2011;25:268-74.

34. Saugstad OD, Aune D. In search of the optimal oxygen saturation for extremely low birth weight infants: a systematic review and meta-analysis. Neonatology 2011;100:1-8.

35. Deulofeut R, Critz A, Adams-Chapman I, Sola A. Avoiding hyperoxia in infants $<$ or $=1250 \mathrm{~g}$ is associated with improved short- and long-term outcomes. J Perinatol 2006;26:700-5.

36. SUPPORT Study Group of the Eunice Kennedy Shriver NICHD Neonatal Research Network. Target ranges of oxygen saturation in extremely preterm infants. N Engl J Med 2010;362:1959-69.

37. Stenson B, Brocklehurst P, Tarnow-Mordi W; U.K. BOOST II trial; Australian BOOST II trial; New Zealand BOOST II trial. Increased 36-week survival with high oxygen saturation target in extremely preterm infants. N Engl J Med 2011;364:1680-2.

38. Carter BG, Carlin JB, Tibballs J, Mead H, Hochmann M, Osborne A. Accuracy of two pulse oximeters at low arterial hemoglobin-oxygen saturation. Crit Care Med 1998;26:1128-33.

39. Bohnhorst B, Peter CS, Poets CF. Detection of hyperoxaemia in neonates: data from three new pulse oximeters. Arch Dis Child Fetal Neonatal Ed 2002;87:F217-9.

40. Cochran DP, Shaw NJ. The use of pulse oximetry in the prevention of hyperoxaemia in preterm infants. Eur J Pediatr 1995;154:222-4.

41. Downes JJ, Vidyasagar D, Boggs TR Jr, Morrow GM 3rd. Respiratory distress syndrome of newborn infants. I. New clinical scoring system (RDS score) with acid-base and blood-gas correlations. Clin Pediatr (Phila) 1970;9:325-31.

42. Ballard JL, Khoury JC, Wedig K, Wang L, Eilers-Walsman BL, Lipp R. New Ballard Score, expanded to include extremely premature infants. J Pediatr 1991;119:417-23.

43. Volpe JJ. Intracranial hemorrhage: Germinal matrix-intraventricular hemorrhage of the preterm infant. In: Volpe JJ, ed. Neurology of the Newborn, 5th edn. Philadelphia, PA: Saunders Elsevier, 2008: 517-88.

44. Zwibel WJ, Pellerito JS. Basic concepts of Doppler frequency spectrum analysis and ultrasound blood flow imaging. In: Zwibel WJ, Pellerito JS, eds. Introduction to Vascular Ultrasonography, 5th edn. Philadelphia, PA: Saunders Elsevier, 2005:61-89. 